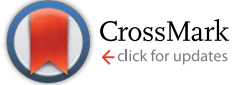

Cite this: RSC Adv., 2015, 5, 55353

Received 5th June 2015

Accepted 18th June 2015

DOI: $10.1039 / c 5 r a 10649 d$

www.rsc.org/advances

\section{Thermal, chemical and morphological properties of carbon fibres derived from chemically pre-treated wool fibres $\dagger$}

\begin{abstract}
Mohammad Mahbubul Hassan, ${ }^{* a}$ Linda Schiermeister $^{\mathrm{b}}$ and Mark Peter Staiger ${ }^{\mathrm{bc}}$
In this work, the feasibility of using wool fibre as a carbon fibre precursor was explored as well as whether chemical treatments to wool fibre can increase the carbon fibre yield and properties of the produced carbon fibres. Wool fibres were treated with a range of chemicals including lignin, tannic acid, polystyrene sulphonate, and chlorine in conjunction with a polyamide resin. The treated fibres were stabilised in air at $160{ }^{\circ} \mathrm{C}$ followed by pyrolysis at $800{ }^{\circ} \mathrm{C}$ under a nitrogen atmosphere. The resulting carbon fibres were characterised in terms of carbon yield, tensile strength, surface roughness, porosity, crystal structure and surface hydrophobicity. The carbon fibre yield was $16.7 \%$ for the untreated while the lignin pre-treatment increased the carbon yield up to $25.8 \%$. Generally the surface of the carbon fibre made from both untreated and treated fibre exhibited high hydrophilicity except the lignin and chlorine/polyamide resintreated fibre which showed hydrophobicity. Although the tensile strength achieved for the various produced carbon fibre was poor compared to a commercially available pitch-based carbon fibre, the developed carbon fibre still can be utilised in thermoplastic composite manufacturing.
\end{abstract}

\section{Introduction}

Carbon fibre is considered to be a high strength, high stiffness technical fibre, comprising of at least $90 \%$ carbon, and usually created by the controlled pyrolysis of an appropriate precursor fibre. Although the origins of carbon fibres can be dated back to the days of Thomas Edison in 1880, ${ }^{1}$ advancements in carbon fibre production have been made only recently. Edison explored various ways to make filaments for the light bulb including the fabrication of carbon fibre, although the fabricated carbon fibre was unsuitable for this task. ${ }^{1}$ Commercial manufacturing of carbon fibre started in 1960s primarily for use in the aerospace industry as stiff, strong and lightweight structural materials. The applications of carbon fibre continue to become more widespread due to their unique chemical, electrical and mechanical properties. ${ }^{2}$ The global demand for a stronger, lighter and stiffer reinforcing fibre, for use in advanced composite materials, has increased in the last decade, ${ }^{3}$ and is forecasted to continual increase.

${ }^{a}$ Food \& Bio-based Products Group AgResearch Ltd., Cnr Springs Road \& Gerald Street, Lincoln, Private Bag 4749, Christchurch 8140, New Zealand. E-mail: mahbubul. hassan@agresearch.co.nz

${ }^{b}$ Department of Mechanical Engineering, University of Canterbury, Private Bag 4800, Christchurch 8140, New Zealand

'The McDiarmid Institute for Advanced Materials and Nanotechnology, P.O Box 600, Kelburn, Wellington 6140, New Zealand

$\dagger$ Electronic supplementary information (ESI) available. See DOI: $10.1039 / \mathrm{c} 5 \mathrm{ra} 10649 \mathrm{~d}$
Carbon fibre is ideally suited as reinforcement in high performance polymer matrix composites, making the combination of high strength and stiffness, light weight and fatigue resistance possible. There is tremendous opportunity for the use of carbon fibre in the structural components of automobiles to reduce vehicle weight and emissions. However, the main barrier to greater use of carbon fibre-reinforced polymer composites in automotive vehicles is the high cost of carbon fibre production. ${ }^{4}$

Almost all carbon fibre production is based on fossil fuelbased high purity polyacrylonitrile (PAN) fibre precursor. The high price of PAN fibre precursor is a relatively large component of the overall manufacturing cost of carbon fibre. The cost of the precursor of carbon fibre constitutes half of the overall cost of manufacturing the final carbon fibre. To reduce the cost of carbon fibre manufacturing and also to meet the continuing growth in demand of carbon fibre, it is necessary to look for lowcost alternative precursors. Renewable resources (e.g. textile wastes, cotton fibre, regenerated cellulosic fibre, wood fibre and lignin) was considered as an alternative to fossil fuel-based materials, to lower the cost and reduce the environmental impact of the carbon fibre precursor. ${ }^{5-9}$ For example, lignin and lignin-polymer blends are potential carbon fibre precursors due to their high carbon yield following pyrolysis and their low cost. $^{10-14}$ However, the commercial exploitation of bio-based fibre as a precursor has not eventuated due to the lower carbon yield and/or poor mechanical properties when compared with carbon fibre derived from PAN. 
Pitch-based carbon fibres have a high yield but poor mechanical properties whereas rayon-based carbon fibres have a low yield but better mechanical properties. ${ }^{15}$ Carbon fibre made from PAN is less suitable for heat shielding due to its high alkaline metal content introduced as a result of the chemical stabilisation treatment stages using hydrogen peroxide in an alkaline medium. ${ }^{\mathbf{1 6}}$

Various studies have focused on the use of chemical treatments to increase the carbon yield during pyrolysis of both traditional and bio-based precursors. For example, the treatment of coal tar pitch with iodine greatly increased the carbon yield during fabrication of carbon fibre due to the iodine acting as a stabilising agent. During pyrolysis, iodine is thought to retard oxidative depolymerisation, while promoting dehydrogenative polymerisation. ${ }^{17,18}$ Various treatments including bromination have also been investigated to enhance oxidation resistance of carbon fibre, which otherwise makes the carbon fibre porous at elevated temperatures (above $500{ }^{\circ} \mathrm{C}$ ) by converting carbon to carbon dioxide..$^{\mathbf{1 9 2 0}}$ The use of iodine treatment to increase the carbon yield has also been extended to biobased precursors, such as silk fibroin. ${ }^{21}$ In other work, sulphuric acid treatment of cellulosic fibre has been shown to increase the carbon yield by $300 \% .^{22}$

Raw wool fibre contains approximately $50 \%$ carbon and 3.7\% sulphur found within disulphide bonds that provide high mechanical rigidity. ${ }^{23,24}$ In spite of the high carbon content of wool fibre, there is scant information in the literature on the conversion of wool fibre into carbon fibre. Chen et al. produced activated carbon powder via pyrolysis of wool fibre at $280{ }^{\circ} \mathrm{C}$ under a flow of nitrogen. ${ }^{25}$

Laufer et al. found that a thin coating of poly(vinyl sulfonic) acid of the order of a few nanometres in thickness improves the thermal stability and flame retardancy of a polyurethane foam. ${ }^{26}$ The presence of sulphur in poly(vinyl sulphonic)acid produces non-flammable sulphur dioxide gas at high temperatures, acting as a flame retardant. It is also known that sulphur species can destroy free-radicals produced during pyrolysis that otherwise accelerate the conversion of carbon fibre into carbon dioxide. $^{27-29}$

Not only tensile strength of the carbon fibre is important in the case of production of carbon fibre from renewable resources, the yield of carbon fibre during pyrolysis is also quite important. If yield is low, the cost of carbon fibre will increase because of lower conversion efficiency. Therefore it is necessary to look for processes that increase carbon fibre yield. It is hypothesised that the high carbon content $(50 \%)$ of wool and also the presence of sulphur (3.70\%) in wool will enhance the carbon fibre yield in comparison to other bio-based precursor materials, making wool a potentially useful carbon fibre precursor.

The target of this work is not only improving the carbon fibre yield but also improving tensile properties of the resultant carbon fibre. In this work, wool fibres were pre-treated with a range of chemicals to increase carbon fibre yield and also the tensile strength of the resultant carbon fibre. The chemicallypre-treated fibres were stabilised in air and then carbonised under nitrogen atmosphere at $800{ }^{\circ} \mathrm{C}$. The carbon field, tensile strength, and also chemical and morphological properties of the resulting carbon fibre were assessed.

\section{Experimental}

\subsection{Materials}

A plain-woven wool fabric of $270 \mathrm{~g} \mathrm{~m}^{-2}$ having 30 ends per inch and 28 picks per inch made from a course wool (mean fibre diameter $=36 \mu \mathrm{m}$ ) was used throughout in this work. Tannic acid, alkaline low sulphonated lignin (weight-average molecular weight, $M_{\mathrm{w}}=\sim 10000$ ), polystyrene sulphonate, acetic acid, and dichloroisocyanuric acid, were purchased from Sigma-Aldrich Chemicals (St. Louis, USA). All of the chemicals were of analytical reagent grade and used as received without any purification. A commercially available pitch-based carbon fibre, Type XN-05-30S, was supplied by Nippon Graphite Fiber Corporation (Japan). The self-crosslinkable epoxy polyamide resin, Hercosett 125, was purchased from Ashland Inc. (Covington, USA). Anthydrin SC, a fluorocarbon polymer emulsion, was purchased from Zschimmer \& Schwarz Chemicals (Lahnstein, Germany). Sandozin MRN, a wetting agent, was purchased from Clariant Chemicals (Muttenz, Switzerland).

\subsection{Chemical treatments}

All the treatments were carried out by an exhaust method in an Ahiba Turbomat laboratory dyeing machine using $30: 1$ liquor ratio. Typically, the bath was filled with water and dosed with $0.2 \mathrm{~g} \mathrm{l}^{-1}$ Sandozin MRN (wetting agent) and $0.5 \mathrm{ml} \mathrm{l}^{-1}$ acetic acid. Table 1 shows the doses of various chemicals used to pretreat wool fibres. The required quantity of chemicals was added and dissolved by mixing thoroughly. Wool fibre was introduced to the bath and the $\mathrm{pH}$ was then adjusted to 4.5 with acetic acid and sodium acetate/sodium hydroxide solution. The temperature was then raised to $70{ }^{\circ} \mathrm{C}$ at $2{ }^{\circ} \mathrm{C} \mathrm{min}{ }^{-1}$ and held for $30 \mathrm{~min}$. After completion of exhaustion treatment, the bath was cooled down to $45{ }^{\circ} \mathrm{C}$ at $2{ }^{\circ} \mathrm{C} \mathrm{min}^{-1}$; after which the bath was drained and the samples were rinsed and dried at $60{ }^{\circ} \mathrm{C}$ in an oven.

The chlorination of wool fabric was carried out according to the method mentioned by Cardamone et al. with dichloro-

Table 1 Carbon yield of various chemically-pretreated wool samples and mechanical properties of the resultant carbon fibres

\begin{tabular}{|c|c|c|c|c|}
\hline $\begin{array}{l}\text { Sample } \\
\text { ID }\end{array}$ & $\begin{array}{l}\text { Chemical } \\
\text { treatment }\end{array}$ & $\begin{array}{l}\text { Carbon yield } \\
\text { at } 800{ }^{\circ} \mathrm{C}(\%)\end{array}$ & $\begin{array}{l}\text { Tensile } \\
\text { strength (MPa) }\end{array}$ & $\begin{array}{l}\text { Elongation } \\
(\%)\end{array}$ \\
\hline $\begin{array}{l}\mathrm{XN}-05 \\
-30 \mathrm{~S}\end{array}$ & - & - & 1100 & 2.0 \\
\hline C & - & 16.7 & 143.2 & 0.4 \\
\hline $\mathrm{T} 1$ & $8 \%$ lignin & 25.8 & 165.7 & 0.5 \\
\hline $\mathrm{T} 2$ & $8 \%$ tannic acid & 22.7 & - & - \\
\hline $\mathrm{T} 3$ & $\begin{array}{l}10 \% \text { polystyrene } \\
\text { sulphonate }\end{array}$ & 19.9 & - & - \\
\hline $\mathrm{T} 4$ & $\begin{array}{l}3 \% \text { fluorocarbon } \\
\text { polymer }\end{array}$ & 19.5 & - & - \\
\hline T5 & $3 \%$ chlorine & 18.2 & 151.2 & 0.4 \\
\hline $\mathrm{T} 6$ & $\begin{array}{l}3 \% \text { chlorine }+2 \% \\
\text { polyamide resin }\end{array}$ & 20.5 & 219.3 & 0.6 \\
\hline
\end{tabular}


isocyanuric acid (DCCA), ${ }^{30}$ but the applied level of DCCA was 3\% on weight of wool (oww). Some of the chlorinated wool was then again treated with $2 \%$ oww Hercosett resin at $60{ }^{\circ} \mathrm{C}$ for 20 minutes at $\mathrm{pH} 8.5$ to 9.0 using a sodium bicarbonate buffer.

The add-on was calculated for different doses of lignin by subtracting the oven-dry weight of the sample before the treatment from the oven dry-weight of the sample after the treatment, divided the value by the oven dry-weight of the sample before the treatment and expressed as a percentage. The ovendrying was carried out in an electrically-heated oven at $105 \pm$ $2{ }^{\circ} \mathrm{C}$ until the weight was no more decreased.

\subsection{Pyrolysis}

A temperature controlled horizontal tube furnace (High Temperature Vacuum Tube Furnace, Model OTF-1200X, MTI Corporation, Richmond, USA) was used to convert pre-treated wool fibres to carbon fibre. All the samples were stabilised by heating under an oxygen environment at $160{ }^{\circ} \mathrm{C}$ for 10 minutes prior to pyrolysis. The wool fabric samples (approximately $1 \mathrm{~g}$ ) were cut into pieces of a size of $125 \times 25 \mathrm{~mm}$ and were loaded into a crucible. Afterwards the crucible was placed in the furnace tube and the tube was purged with a constant flow of $100 \mathrm{ml} \mathrm{m^{-1 }}$ nitrogen gas for $30 \mathrm{~min}$ before heating started as well as during heating. Each sample was heated to $200{ }^{\circ} \mathrm{C}$ at $2{ }^{\circ} \mathrm{C}$ $\mathrm{min}^{-1}$, and held for $15 \mathrm{~min}$. The sample was then heated to 800 ${ }^{\circ} \mathrm{C}$ at $2{ }^{\circ} \mathrm{C} \min ^{-1}$ and held for $20 \mathrm{~min}$. After cooling the reactor to room temperature at $5{ }^{\circ} \mathrm{C} \min ^{-1}$ under a constant flow of nitrogen $\left(100 \mathrm{ml} \mathrm{min}^{-1}\right)$, the produced carbon fibre sample was removed from the furnace and placed in a desiccator until various analyses were carried out.

\subsection{Thermal characterisation}

An atmospheric pressure thermo-gravimetric analyser (TGA) Model SDT Q600 made by TA Instruments (New Castle, USA) was used to study pyrolysis behaviour as well as for the measurement of carbon yield of untreated and various treated wool fibres. All TGA runs employed nitrogen (99.99\% pure and food-grade) as purge gas for the furnace with a constant flow rate of $100 \mathrm{ml} \mathrm{min}{ }^{-1}$. For each run, 7-10 $\mathrm{mg}$ of sample was loaded in a platinum pan. In the first test series, an untreated sample was heated to $400,450,500,550,600,650,700,750$ and $800{ }^{\circ} \mathrm{C}$ at a linear rate of $10{ }^{\circ} \mathrm{C} \mathrm{min}^{-1}$ under constant nitrogen gas flow $\left(100 \mathrm{ml} \mathrm{min}^{-1}\right)$, held for 10 minutes, and slowly cooled down to room temperature by switching off the heater. The carbon yield was calculated by dividing the sample's mass as measured at the pyrolysis temperature $\left(W_{\mathrm{b}}\right)$ by the dry mass measured at the end of the drying period at $105{ }^{\circ} \mathrm{C}\left(W_{\mathrm{a}}\right)$ according to the following formula:

$$
\text { Carbon yield }(\%)=\frac{W_{\mathrm{b}}}{W_{\mathrm{a}}} \times 100
$$

Py-GC/MS analysis of wool fibre was performed using a CDS Analytical Pyroprobe 5250 (CDS Analytical Inc., Oxford, USA) and an Agilent HP 6890 gas chromatography (Agilent Technologies, Santa Clara, USA), coupled to an Agilent HP 5973 mass spectrometer. Wool fibres were pyrolysed at 300 to $400{ }^{\circ} \mathrm{C}$ and also 400 to $600{ }^{\circ} \mathrm{C}$ at $10^{\circ} \mathrm{C} \mathrm{min}{ }^{-1}$ under helium atmosphere and the evolved gas were analysed by GC/MS. For full details of experimental methods, see the electronic ESI. $\dagger$

\subsection{Mechanical and chemical characterisation}

The tensile strength at break and elongation at break were measured with an Instron Universal Testing Machine (Model 4204 , Instron Inc., Norwood, USA) using a load cell of $10 \mathrm{~N}$ at 22 $\pm 2{ }^{\circ} \mathrm{C}$ and $65 \pm 2 \% \mathrm{RH}$ at a gauge length of $10 \mathrm{~mm}$ and a strain rate of $2 \mathrm{~mm} \mathrm{~min}^{-1}$. A single carbon fibre yarn was glued to a paper holder by using a cyanoacrylate adhesive. For each type of fibre at least twelve fibres were tested and the average is reported here.

FT-IR of carbon residues remaining after TGA analysis for each sample was carried out using a Perkin Elmer FT-IR Spectrum 2000 spectrometer (Perkin Elmer, Akron, USA). The control sample that was heated to temperatures from 400 to $800{ }^{\circ} \mathrm{C}$ was scanned by FT-IR to find out the lowest temperature at which carbon is left. The ash-KBr mixtures were ground and pressed to obtain IR-transparent disks. For each sample 32 scans were carried out and the average is reported here. In the same way carbon fibres produced in the multistage pyrolysis were also analysed by FT-IR. Elemental analysis of carbon fibre produced from control, lignin and chlorine-Hercosett-treated wool fibres were carried out at Campbell Microanalytical Laboratory (University of Otago, New Zealand).

Carbon residues of selected samples were analysed by using an X-ray diffractometer to determine the crystal structure as well as the crystallinity. Diffraction patterns of the samples were collected on a PW1820/1710 X-ray diffractometer (Phillips, Eindhoven, The Netherlands) using $\mathrm{Cu}-\mathrm{K} \alpha$ radiation $(50 \mathrm{kV}, 40$ $\mathrm{mA})$. The samples were scanned over a $2 \theta$ range $3-100^{\circ}$ in a stepscan for $0.02^{\circ}$ per step. The apparent crystallite thickness $\left(L_{\mathrm{c}}\right)$, the apparent layer-plain length parallel to the fibre axis $\left(L_{\mathrm{a}}\right)$, and the average inter-layer spacing $(d)$ were calculated using the following Bragg-Scherrer formula:

$$
\begin{aligned}
& d=\frac{\lambda}{2 \sin \theta} \\
& L=\frac{K \lambda}{\beta \cos \theta}
\end{aligned}
$$

where, $\theta$ is the Bragg angle of peaks $\left(^{\circ}\right), \lambda$ is the wave length of the X-ray used (in our case it is $0.1541 \mathrm{~nm}$ ), $\beta$ is the half-height full width of peak (radian) and $K$ is the form factor (the value of $K$ for $L_{\mathrm{c}}$ and $L_{\mathrm{a}}$ is 0.89 for and 1.84, respectively).

\subsection{Scanning electron microscopy (SEM)}

The surface and internal structural characteristics of carbon fibres produced from untreated and various treated wool fibres were assessed by scanning electron microscopy. Carbonised samples were imaged using a JEOL JSM-6100 (JEOL, Tokyo, Japan) scanning electron microscope without any conductive coating as the samples were conductive enough to prevent 
electrical discharge. SEM scanning of both cracked and longitudinal surfaces was carried out.

\subsection{Contact angle}

Various treated wool fabrics were carbonised at $800{ }^{\circ} \mathrm{C}$ and the resultant carbonised specimens were used to measure the contact angle. The contact angle was measured in dynamic mode by using a KSV CAM 100 (KSV Instruments, Helsinki, Finland) Contact Angle Measurement Apparatus. For each sample, contact angle was measured at five places and the average contact angle was reported. For each sample, the first measurement was taken $0 \mathrm{~s}$ after placing a droplet of water and then at $15 \mathrm{~s}$ intervals until $90 \mathrm{~s}$.

\section{Results and discussion}

\subsection{Thermal properties and carbon yield}

Initially, we investigated the thermal properties of untreated wool fibre at $400,450,500,550,600,650,700,750$ and $800{ }^{\circ} \mathrm{C}$ to identify the chemical changes occurs at various temperatures during pyrolysis. The wool fibres were heated up to the specified temperatures at $10{ }^{\circ} \mathrm{C} \mathrm{min}{ }^{-1}$ and held for $10 \mathrm{~min}$. We analysed the residual carbonaceous materials produced by wool fibres pyrolysed at various temperatures during the thermogravimetric analysis by FTIR (Fig. 1). The broad peak visible at $3200-3400 \mathrm{~cm}^{-1}$ for all the samples could be attributed to hydroxyl groups. ${ }^{31}$ As temperature increases, the intensity of the broad peak of hydroxyl groups is decreased. The spectrum of wool fibre shows an aromatic $\mathrm{C}-\mathrm{H}$ stretching band at 3071 $\mathrm{cm}^{-1}$, which disappeared for the wool fibre pyrolysed at $800{ }^{\circ} \mathrm{C}$. The peaks at 2915 and $2945 \mathrm{~cm}^{-1}$ are corresponding to $\mathrm{CH}_{2}$ asymmetric and symmetric stretching bands, respectively, and their intensity decreased with an increase in temperature. ${ }^{32} \mathrm{~A}$ new absorption band was appeared at $2850 \mathrm{~cm}^{-1}$ for the samples heated from $600{ }^{\circ} \mathrm{C}$ which could be attributed to the methylene bridge. The peak at around $1650 \mathrm{~cm}^{-1}$ could be attributed to the $\mathrm{C}=\mathrm{O}$ stretch of the peptide carbonyl (amide I vibration), which is shifted towards $1600 \mathrm{~cm}^{-1}$ with the increase in temperature, suggest the formation of $-\mathrm{C}=\mathrm{C}$ - which may have aromatic structure. ${ }^{8}$ However, the intensity of the absorption peak for the vibration of the aromatic skeleton at $1645 \mathrm{~cm}^{-1}$ gradually decreased with an increase in temperature and almost disappeared for the fibre pyrolysed at $800{ }^{\circ} \mathrm{C}$. The intensity of the sharp amide (II) band visible at around 1230 $\mathrm{cm}^{-1}$ for wool fibre precursor gradually decreased with an increase in temperature and almost disappeared in the spectrum of wool fibre pyrolysed at $800{ }^{\circ} \mathrm{C}$. The disappearance of $-\mathrm{OH},-\mathrm{CH}_{2}, \mathrm{C}=\mathrm{O}$ and $-\mathrm{C}=\mathrm{C}$ - suggest formation of aromatic cyclic carbon structure and transformation into cyclic carbon framework. ${ }^{33,34}$

Fig. 2 shows TGA curve of untreated control wool fibres heated at various temperatures. It can be seen that weight loss of wool mainly occurs at three stages, 30 to $120^{\circ} \mathrm{C}, 220$ to $400{ }^{\circ} \mathrm{C}$ and 400 to $800{ }^{\circ} \mathrm{C}$, but the highest rate of weight loss occurs between 220 and $400{ }^{\circ} \mathrm{C}$. The first stage of weight loss occurring from 30 to $105{ }^{\circ} \mathrm{C}$, was a decrease of $7-10 \%$ due to the loss of

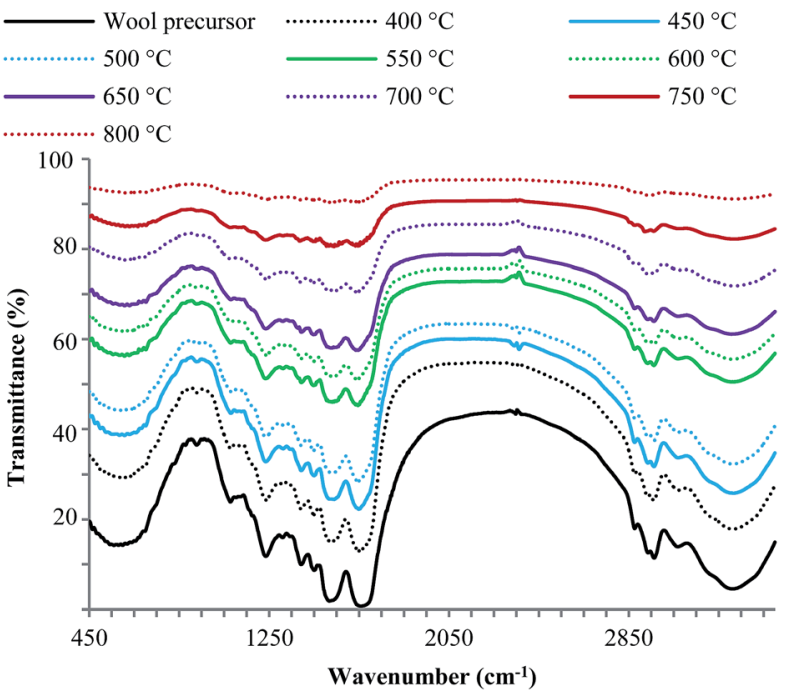

Fig. 1 FT-IR spectra obtained after the pyrolysis of untreated wool fibre under a nitrogen atmosphere at different temperatures.

water physically bound to wool as the moisture content of wool at $65 \%$ relative humidity is $11 \% .^{35}$ The second stage of weight loss, occurring between 220 to $400{ }^{\circ} \mathrm{C}$, was a further 20 to $23 \%$ reduction, and is associated with the rupturing of hydrogen bonds of the peptide helical structure, crosslinking through condensation reaction and the ordered regions undergo a solid to melted phase change. ${ }^{36}$ Then the cleavage of the disulphide bonds occur along with emission of few volatile gasses including hydrogen sulphide gas and sulphur dioxide. ${ }^{37}$ This is the stage where the most rapid rate of weight loss was observed. During this process, the $\alpha$-helix structure of wool is broken down through breaking down various chain linkages, peptide bridges and other lateral chains that ultimately leads to skeletal breakdown of the fibre. ${ }^{38}$ In the third stage, weight loss occurs quite slowly, as the most of the organic part is broken down. The structural changes occur in wool fibre at various stages of heating during pyrolysis is shown in Scheme $1 .^{16,39}$

Py-GC/MS analysis of fibre was carried out to elucidate wool fibre pyrolysis mechanism by identifying the evolved gaseous

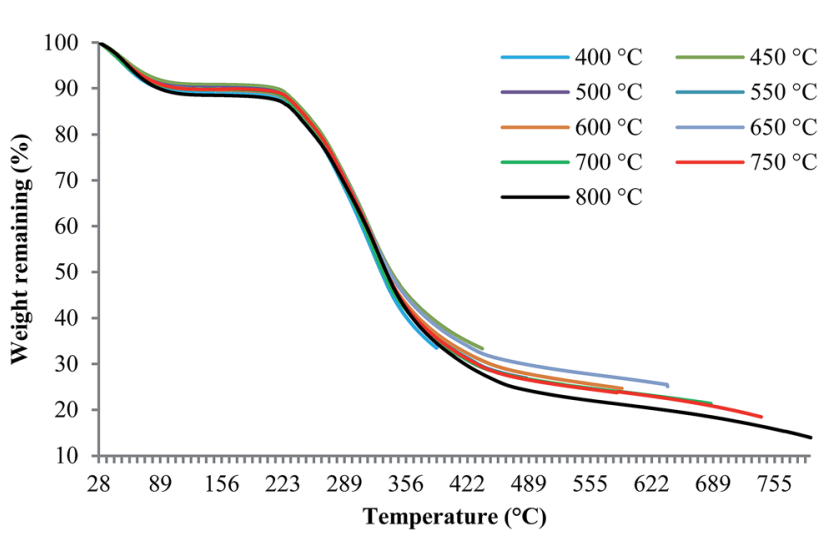

Fig. 2 Weight loss as a function of the temperature for untreated wool fibre that has been pyrolysed at temperatures between 400 and $800^{\circ} \mathrm{C}$. 


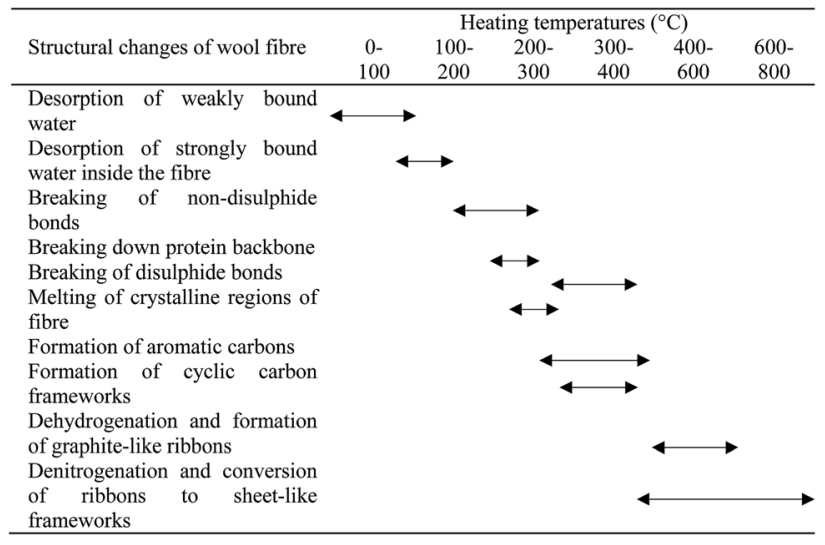

Scheme 1 Structural changes at various stages of pyrolysis of wool fibre. ${ }^{16,39}$

compounds. They were identified on the basis of mass spectra and retention times. TGA data shown in Fig. 2 indicate that during pyrolysis chemical changes in wool mainly occur at room temperature to 220,220 to 400 and above $400{ }^{\circ} \mathrm{C}$. Below $250{ }^{\circ} \mathrm{C}$ mainly loss of gaseous compounds, such as water, hydrogen sulphide and sulphur dioxide (due to breakage of disulphide bonds in wool), takes place. The GC spectra of wool fibre pyrolysed at 300 to 440 and 400 to $600{ }^{\circ} \mathrm{C}$ are shown in Fig. S1 and S2 (see ESI $\dagger$ ). A large number of compounds could not be identified from the mass spectra; these are listed as 'unknown' in the Tables S1 and S2 (see the ESI†). Many of these peaks are possibly consist of a number of co-eluting compounds, which complicate the mass spectral interpretation. The chromatograms of wool fibre pyrolysed at two temperature ranges indicate the complex nature of the samples. However, identification of 45 and 41 compounds was possible in the case of pyrolysis from 300 to $400{ }^{\circ} \mathrm{C}$ and 400 to $600{ }^{\circ} \mathrm{C}$, respectively. The compounds generated in both 300 to 400 and 400 to $600{ }^{\circ} \mathrm{C}$ stages were similar but at the higher temperature regions several new compounds including styrene, xylene, phenyl alanine methyl ester, and methyl indole have been identified. The number of compounds generated decreased with an increase in temperature. The Tables S1 and S2 (see the $\mathrm{ESI} \dagger$ ) show the identified compounds along with their relative peak areas, calculated as a percentage of the total area of all identified peaks (Fig. S1 in the ESI $\dagger$ ). The main decomposition products are aromatics and phenols generated from the decomposition of various amino acids. During the pyrolysis of various amino acids, Galios et $a .^{40}$ found that mainly methylation, dimerisation, cyclisation, decarboxylation and denitrogenation reactions occurred. The formation of various nitrile and amine compounds at 300 to $400{ }^{\circ} \mathrm{C}$ indicates the removal of nitrogen from the wool keratin structure during pyrolysis. The formation of acetic acid, 2-methyl butanoic acid and 4-methyl pentanoic acid indicates decarboxylation reactions also occurred at relatively lower temperatures.

During pyrolysis of keratin, not only bond breaking reactions take place but at the same time crosslinking reactions also happens, which usually takes place between 250 to $300{ }^{\circ} \mathrm{C} .{ }^{39}$ At below $300^{\circ} \mathrm{C}$, disulphide bridges of wool keratin are broken down with a subsequent collapse of the polypeptides and these polypeptides interact with each other more randomly resulting in a wide range of reactions forming wide range of compounds. At above $400{ }^{\circ} \mathrm{C}$ cyclisation reactions are expected because of the formation of reactive radicals within the melted residue. In the case of polyacrylonitrile it was found that dehydrogenation takes place 400 to $600{ }^{\circ} \mathrm{C}$ forming graphite like ribbons and denitrogenation takes place at above $600{ }^{\circ} \mathrm{C}$ forming sheet-like structures by converting the graphite-like ribbons formed at 400-500 ${ }^{\circ} \mathrm{C} .{ }^{16,39,41}$ Similar reactions possibly occurred in the pyrolysis of wool fibre at high temperatures and formed carbon fibre.

Fig. 3a shows the thermo-gravimetric curves of wool fibres pre-treated with various chemicals. In general, the weight loss of the variously pre-treated wool fibres was similar to that of the untreated wool fibre, although between 400 and $800{ }^{\circ} \mathrm{C}$ the weight loss was considerably lower when compared with the untreated wool fibre. In the case of wool fibre treated with lignin, the weight loss reaches a plateau and for other treated fibres the weight loss slowed down, while untreated wool continues to gradually lose weight with an increase in temperature. All the treatments increased the thermal stability of wool between 400 and $800{ }^{\circ} \mathrm{C}$ compared to untreated wool fibre (Fig. 3a). Of the treatments investigated, lignin and tannic acid provided the highest thermal stability and the lowest by the chlorination.
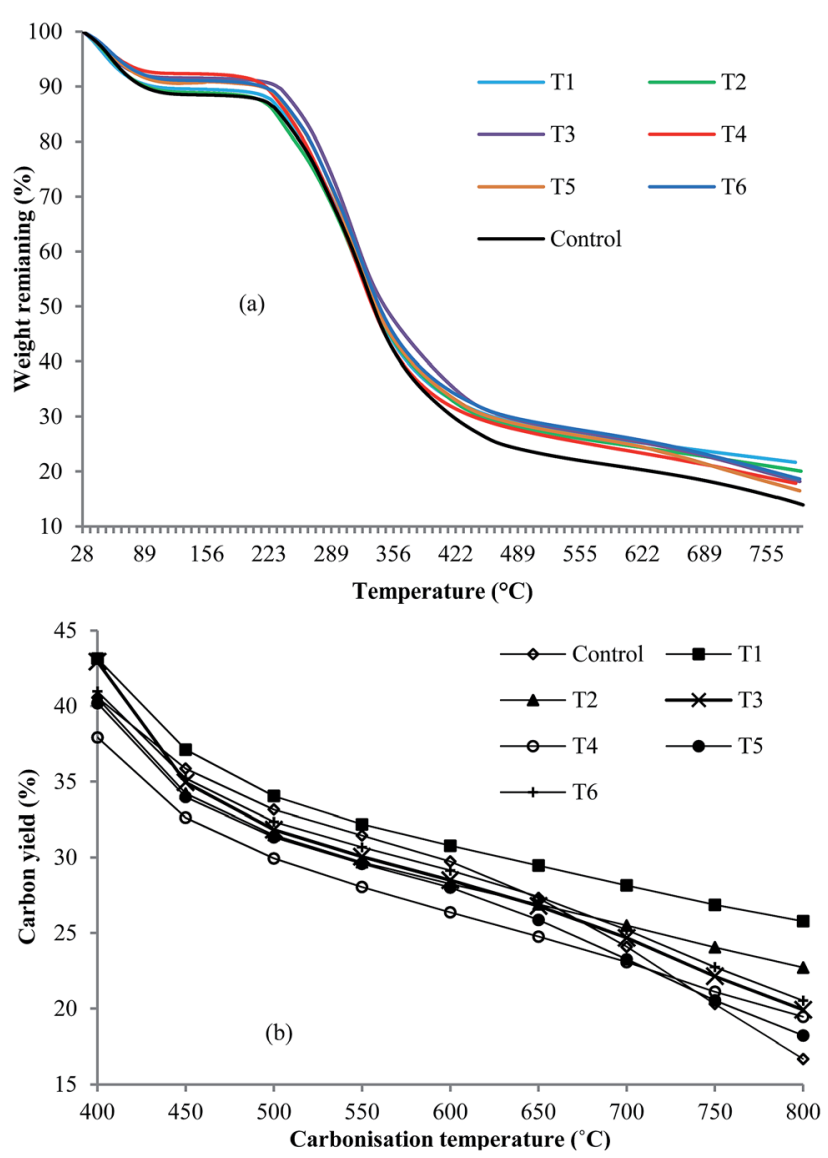

Fig. 3 Weight loss (a) and carbon yield (b) of the untreated and treated wool fibre as a function of the temperature. 
Table 1 shows the carbon yield produced by various treated wool fibres at $800{ }^{\circ} \mathrm{C}$. The pyrolysis of the untreated wool at $800{ }^{\circ} \mathrm{C}$ resulted in a carbon yield of only $16.7 \%$. In contrast, most of the treatments considerably increased the carbon yield of the untreated wool fibre. The tannic acid and lignin treatments resulted in the highest carbon yields of 22.7 and $25.8 \%$, respectively.

The polystyrene sulphonate pre-treated wool also showed improved thermal stability at high temperatures. However, the improvement in the carbon yield achieved for the polystyrene sulphonate grafted wool was only a marginal, although polyvinyl sulphonate is reported to improve the thermal stability of polyurethane foam. ${ }^{24}$ During heating treatment, lignin and tannic acid both probably formed crosslink between carboxyl groups of amino acids of wool keratin thorough condensation reactions, which improved the thermal stability and reduced their degradation. In the case of Hercosett resin and polystyrene sulphonate-treatment, those polymers only formed a thin layer on the surface of wool fibres and therefore showed limited effect on thermal stability.

Fig. $3 \mathrm{~b}$ shows the effect of temperatures on carbon fibre yield for the control and various chemically pre-treated wool fibres carbonised at $400{ }^{\circ} \mathrm{C}$ to $800{ }^{\circ} \mathrm{C}$. Obviously, yield decreased with an increase in the temperature as degradation of wool fibre as well as the conversion of carbon to carbon dioxide increased with an increase in temperature. Carbon yields for the lignintreated wool fibre (Sample T1) was higher at all the temperatures studied compared to the carbon yield achieved for the control and the other chemically treated wool fibres. The control fibre showed higher carbon yields up to $600{ }^{\circ} \mathrm{C}$ than the chemically pre-treated wool fibres (except the wool fibre treated with lignin); after which its carbon yield rapidly decreased with an increase in temperature. The results indicate that chemical pre-treatments produced thermally stable residues at 400-500 ${ }^{\circ} \mathrm{C}$ those decomposed slowly at higher temperatures.

\subsection{Add-on of lignin}

The lignin treatment of wool fibre was selected for an add-on study as it provided the greatest increase in the thermal stability and carbon yield compared with the untreated wool fibre. The add-on (adsorption and absorption of lignin by wool) decreased with an increase in pH (Fig. 4a). The highest uptake of lignin was achieved at a pH of 3 , while the lowest uptake was observed at a pH of 8 . The isoelectric point of wool in water is 4.5 , below which wool fibre is cationic and above it anionic. ${ }^{42}$

Lignin is anionic due to the presence of the sulphonate groups. Thus, the sorption of lignin onto wool fibre is hindered at a $\mathrm{pH}$ above 4.5 due to electrostatic repulsion. Moreover, the degradation of wool (and thus weight loss) increases with an increase in the $\mathrm{pH}$. The lignin molecules are large in size and therefore their absorption into wool fibre interior is difficult and they only deposits on fibre surface. The absorption is quite dependent on the ionic interaction and once equilibrium is reached, they are not adsorbed even if the applied dose is increased. Only low molecular weight components of lignin were absorbed into wool and the high molecular components were
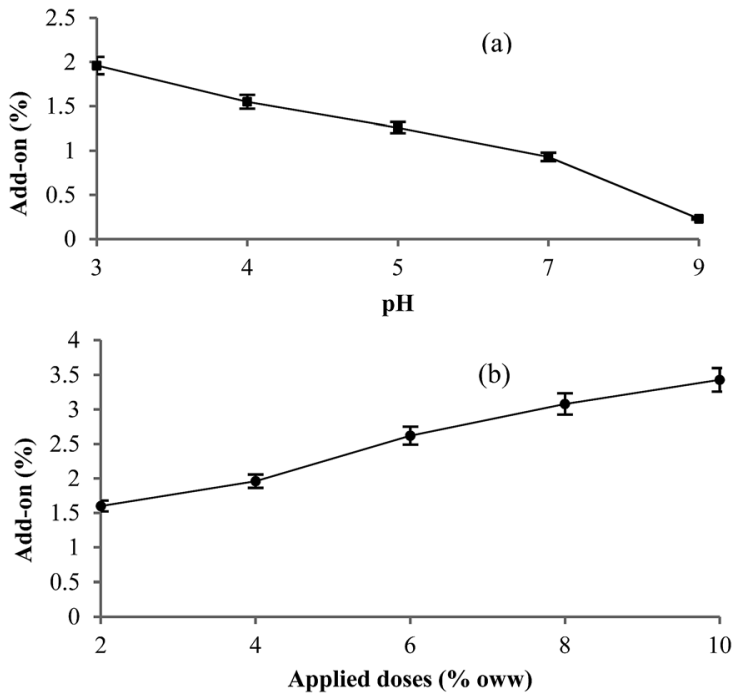

Fig. 4 Effect of the (a) $\mathrm{pH}$ and (b) applied dose on the uptake of lignin by wool fibre.

adsorbed by wool. The uptake of lignin by wool fibre increased with an increase in the applied dose of lignin (Fig. 4b). An applied dose of $8 \%$ oww was found to be optimal since beyond this the uptake began to plateau. Hence, the optimal $\mathrm{pH}$ and applied dosage were 3 and $8 \%$ oww, respectively.

\subsection{Characterisation of carbon fibres}

The produced carbon fibres were quite stiff but almost brittle except the one produced from the wool fibre pre-treated with lignin and chlorine-Hercosett. The produced carbon fibre specimens were characterised by tensile strength, surface contact angle measurement, SEM, FT-IR and XRD analysis.

Mechanical properties. Table 1 shows the tensile strength and elongation at break of carbon fibres produced from untreated and various treated wool. It is evident that all of the carbon fibres produced from untreated and various pre-treated wool showed poor tensile strength and elongation at break compared to the commercial $\mathrm{XN}-05-30 \mathrm{~S}$ carbon fibre. The average tensile strength and elongation at break of the $\mathrm{XN}-05$ $30 \mathrm{~S}$ was $1100 \mathrm{MPa}$ and $2 \%$ respectively. Of the pre-treatment studied for wool fibre, the highest tensile strength was shown by the carbon fibre prepared from the chlorine-Hercosett treated wool and it was only 219.3 MPa.

Surface properties of carbon fibre derived from wool fibre. Fig. 5 shows the photographs of water droplets on the surface of carbon fibres produced from untreated and treated wool fibres. Carbon fibre produced from the untreated wool was highly hydrophilic such that it was not possible to measure the surface contact angle since the water droplet was rapidly absorbed by the sample. Wool fibre treated with tannic acid (T2), polystyrene sulphonate (T3), fluorocarbon resin (T4), and chlorine (T5) exhibited similar surface properties to the untreated wool fibre. In contrast, the carbon fibre made from lignin (T1) and chlorine-Hercosett treated wool (T6) exhibited hydrophobicity, making it possible to measure the contact angle (Table 2). 
Carbon fibre derived from the lignin-treated wool (T1) was hydrophobic such that the contact angle did not decrease even after $45 \mathrm{~s}$. Carbon fibre produced from T6 initially exhibited a higher contact angle than the T1 carbon fibre, although the contact angle decreased with time.

Elemental compositions. Only the carbon fibre produced from the high carbon yielding treated wool fibres (lignin and chlorine-Hercosett) were considered for compositional analysis. The wool fibre precursor had $\mathrm{C}, \mathrm{H}, \mathrm{N}$ and $\mathrm{S}$ at 50.5, 6.80, 16.5 and $3.7 \%$ respectively. Elemental analysis results (Table 3) revealed that in carbon fibres produced from lignin and chlorine-Hercosett-treated wool had carbon content similar to the carbon content observed for the carbon fibre produced from untreated wool. However, carbon fibre produced from lignintreated wool (T1) showed lower $\mathrm{H}$ and $\mathrm{N}$ content but higher S content compared to the carbon fibre produced from untreated wool fibre. On the other hand, the carbon fibre produced from the chlorine-Hercosett-treated wool fibre lower $\mathrm{H}$ content but higher $\mathrm{N}$ and $\mathrm{S}$ content compared to the carbon fibre produced from untreated wool.

Carbon fibre produced from untreated and chlorineHercosett-treated wool fibre had a carbon content of 77.4 and $77.6 \%$, respectively, while lignin-sulphonate-treated wool fibre had a slightly higher carbon content of $78.4 \%$ (Table 3 ). On the other hand, lignin and chlorine-Hercosett-treated wool has the same content of hydrogen $(1 \%)$ which was lower than that

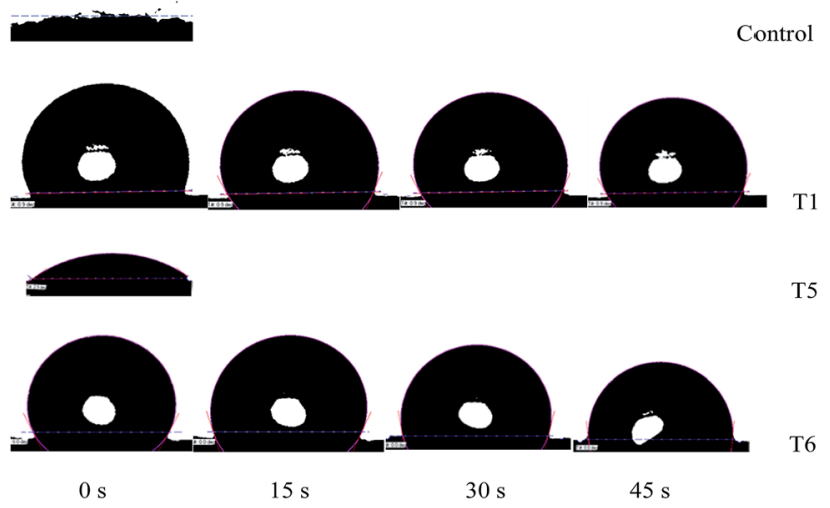

Fig. 5 Photographs of water droplets on the surface of carbon fibres produced from untreated and treated wool fibres.

Table 2 Dynamic contact angle of surface of carbon fibres produced from various treated wool

\begin{tabular}{lcccc}
\hline & \multicolumn{4}{c}{ Contact angle $\left(^{\circ}\right)$ at } \\
\cline { 2 - 5 } Treatments ID & $0 \mathrm{~s}$ & $15 \mathrm{~s}$ & $30 \mathrm{~s}$ & $45 \mathrm{~s}$ \\
\hline Control & 0 & 0 & 0 & 0 \\
T1 & 115.7 & 115.7 & 115.7 & 115.6 \\
T2 & 0 & 0 & 0 & 0 \\
T3 & 0 & 0 & 0 & 0 \\
T4 & 0 & 0 & 0 & 0 \\
T5 & 37.0 & 0 & 0 & 0 \\
T6 & 122.21 & 115.3 & 104.0 & 91.5
\end{tabular}

Table 3 Elemental analysis of carbon fibres produced from the control, lignin, and chlorine-Hercosett pre-treated wool fibres

\begin{tabular}{lllll}
\hline & \multicolumn{2}{l}{ Elements (\%) } & & \\
\cline { 2 - 5 } Treatments & $\mathrm{C}$ & $\mathrm{H}$ & $\mathrm{N}$ & $\mathrm{S}$ \\
\hline Control & 77.42 & 1.35 & 10.48 & 0.22 \\
T1 & 77.45 & 1.00 & 10.23 & 0.27 \\
T6 & 77.60 & 1.12 & 10.60 & 0.26
\end{tabular}

available in the carbon fibre made from the untreated wool. The results indicate that the carbon fibre produced from the untreated wool fibre might have a higher number of hydroxyl groups than that produced from the lignin and chlorineHercosett-treated wool fibre.

Fourier transform infra-red spectroscopy. Fig. 6 shows FT-IR spectra of carbon fibre produced from various pre-treated wool at $800{ }^{\circ} \mathrm{C}$. Carbon fibres produced from the untreated, lignin and chlorine-Hercosett treated wool exhibit a broad peak between 3200 and $3400 \mathrm{~cm}^{-1}$ in the FT-IR spectra that is attributed to hydroxyl groups. ${ }^{29}$ In the case of carbon fibre produced from the chlorine-treated wool fibre, that band shifted to $3300-3500 \mathrm{~cm}^{-1}$ with a peak at $3450 \mathrm{~cm}^{-1}$, which could be attributed to loosely bound water molecules.

The spectrum of carbon fibre produced from untreated wool also shows weak bands of methylene bridges at $2850 \mathrm{~cm}^{-1}$ as well as asymmetric and symmetric stretching vibration of $\mathrm{CH}_{2}$ bands, 2915 and $2950 \mathrm{~cm}^{-1}$ respectively. The spectra of carbon fibre prepared from untreated and chlorinated wool fibres show two broad peaks at around 1100 and $1540 \mathrm{~cm}^{-1}$. The bands shown at 1100 and $1540 \mathrm{~cm}^{-1}$ could be attributed to stretching vibrations of $\mathrm{C}-\mathrm{O}-\mathrm{C}$ and $\mathrm{C}=\mathrm{C}$ bonds respectively. In the case of carbon fibre prepared from the chlorinated wool, the band shown at $1100 \mathrm{~cm}^{-1}$ was broader and also showed higher intensity than the carbon fibre produced from the untreated wool. On the other hand, carbon fibres produced from the wool fibres treated with lignin and chlorine-Hercosett also showed a band at $1540 \mathrm{~cm}^{-1}$, but no band was shown at $1100 \mathrm{~cm}^{-1}$. Thus, it is reasonable to presume that the higher hydrophilicity of carbon fibre produced from untreated, and chlorinated wool is

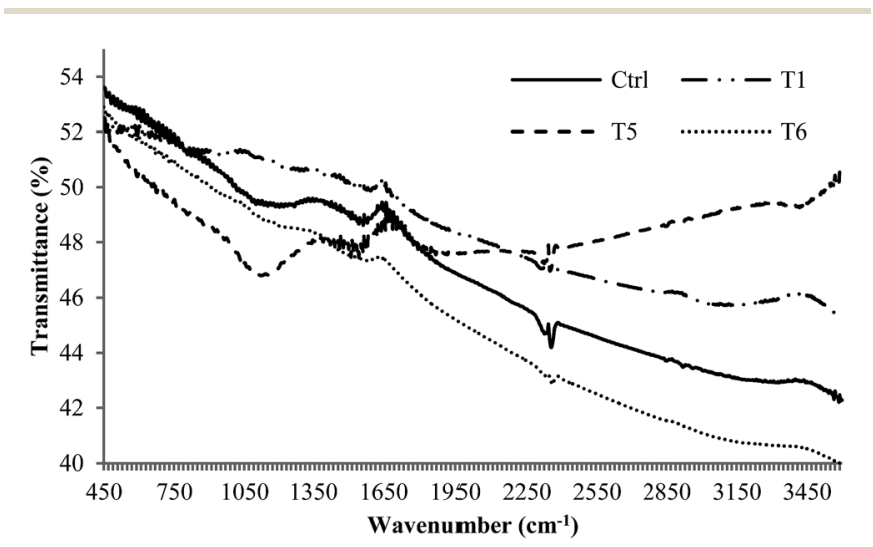

Fig. 6 FTIR spectra of untreated control and variously pretreated wool fibre that have been pyrolysed at $800^{\circ} \mathrm{C}$. 
due to presence of a higher number of hydroxyl and carboxyl groups.

Effect of pre-treatment on the surface morphology of carbon fibre. The change in morphology of the carbon fibre made from the pyrolysis of variously treated wool fibres was investigated by examining both the fracture surface and outer surface of the fibre. It is well known that the surface of the wool fibre consists of scales such that wool fibre exhibits a rough exterior surface. Therefore, it could be expected that the surface of carbon fibre produced from wool fibre might also be non-uniform.

The production of defect-free, low porosity carbon fibre is critical for maximising the strength of carbon fibre. ${ }^{43}$ Many grooves were observed on the surface of the ribbon-shaped carbon fibre made from untreated and pre-treated wool fibre (Fig. 7). In addition, the surface of carbon fibre made from untreated wool fibre was observed to be wavy with grooves sizing from 100 to $500 \mathrm{~nm}$. In general, carbon fibre produced from wool fibre was non-porous; this was attributed to a slow heating rate allowing minimal shrinkage and the gradual release of volatiles. Most of the carbon fibre produced from pre-treated wool fibre showed uneven surface, while the lignin-treated wool fibre produced carbon fibre with a particularly smooth surface.

Lignin is a high molecular weight biopolymer and therefore was not absorbed into fibres, rather deposited on their surface covering the inter-scales area and made the surface smooth. During pyrolysis, lignin reacted with the carboxyl groups of wool through condensation reaction and therefore the produced carbon fibre had smooth surface. The other chemical compounds were absorbed into wool and therefore the surface produced was wavy. The surface of carbon fibre produced from tannic acid-treated wool fibre (T2) was less wavy and smooth compared to that from untreated wool fibre. The surface of carbon fibre produced from chlorinated and chlorine + Hercosett treated wool fibre was wavy, while that from chlorine + Hercosett treated wool fibre was uniformly covered with 200$350 \mathrm{~nm}$ particulates. It is thought the Hercosett resin coating shrinks after pyrolysis, producing the fine particulates observed on the surface of carbon fibre. It is known that nano sized particulates on a surface can produce superhydrophobicity. ${ }^{44,45}$ Therefore, the reason of hydrophobicity shown by the carbon fibre surface produced from the chlorine-Hercosett-treated wool fibre is the presence of nano particulates on its surface.

Examination of the fracture surfaces of the various carbon fibres revealed that all of the carbon fibre produced was free of significant bulk porosity (Fig. 7). In general, the presence of pores was limited to the first few nanometres into the surface of the carbon fibre. The carbon fibre produced from the untreated wool fibre was oval in cross-section, while that from lignintreated wool fibre was perfectly circular. In contrast, carbon fibres produced from tannic acid, chlorine or chlorine-Hercosett pre-treated wool fibre were more ribbon-like.

\subsection{WAXD study of carbon fibre as a function of wool fibre pre-treatment}

WAXD was carried out on untreated and variously pre-treated wool fibre that had been carbonised at $800{ }^{\circ} \mathrm{C}$ (Fig. 8). All of

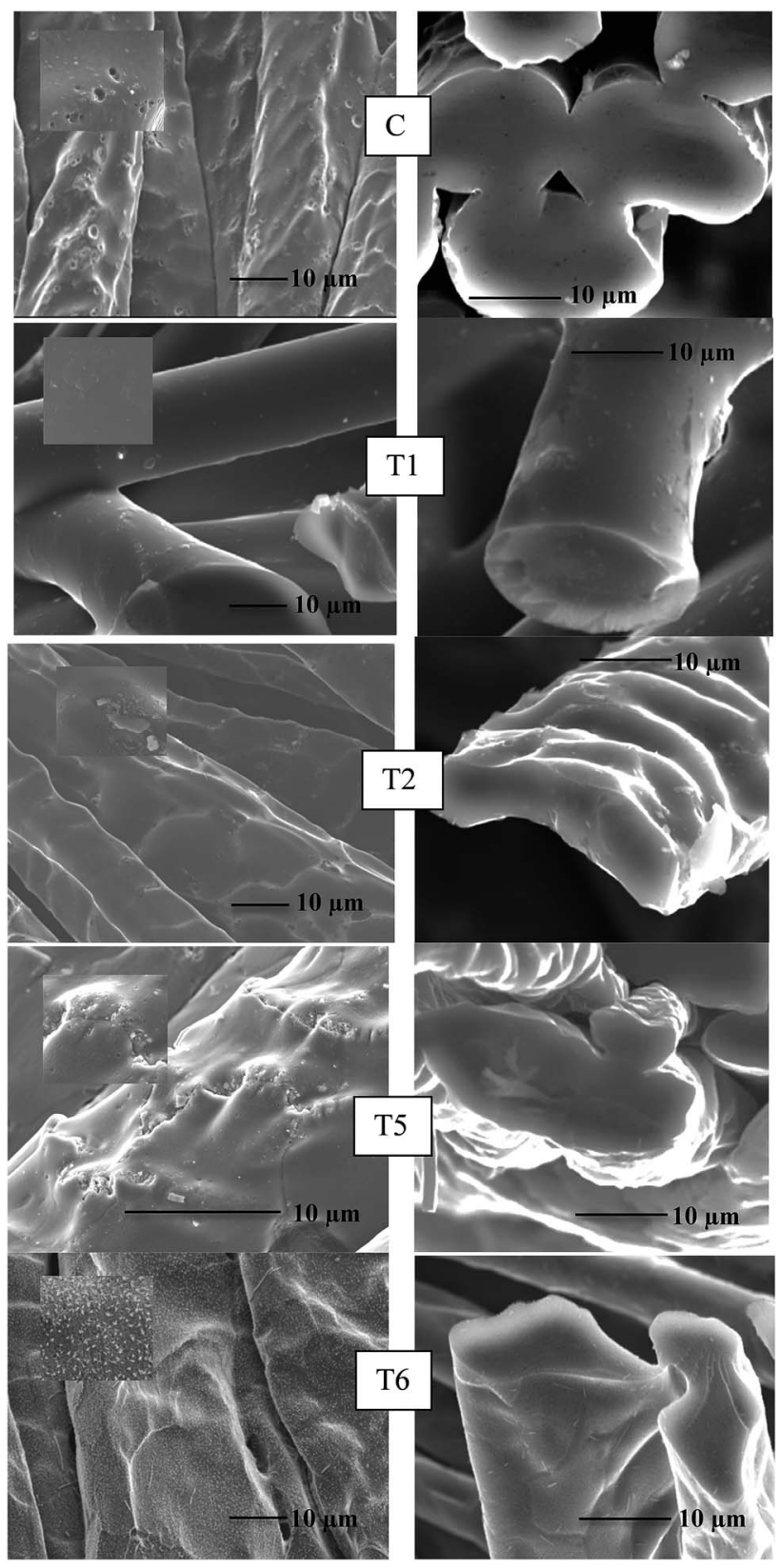

Fig. 7 Scanning electron micrographs of the exterior surface (left) and the fractured surface of carbon fibre produced from untreated and variously pre-treated wool fibre by pyrolysis at $800^{\circ} \mathrm{C}$ (inset: enlarged image).

the various carbonised wool fibres produced a broad diffraction peak cantered at around $2 \theta=24.3^{\circ}$, indicative of the presence of an amorphous phase. All of the carbon fibre samples also exhibited a low, broad peak at around $2 \theta=43^{\circ}$ in their diffractograms that is assigned to the turbostratic band of disordered carbon materials (100). Although the peaks were not as sharp as that of pure carbon, they are direct evidence for the presence of carbon in all of the carbonised wool fibre samples examined in this work.

It is evident that the treatments affected the average interlayer spacing as the value $d_{002}$ increased from 0.3646 for the control to 0.3724 for the chlorinated wool. The minimal effect 


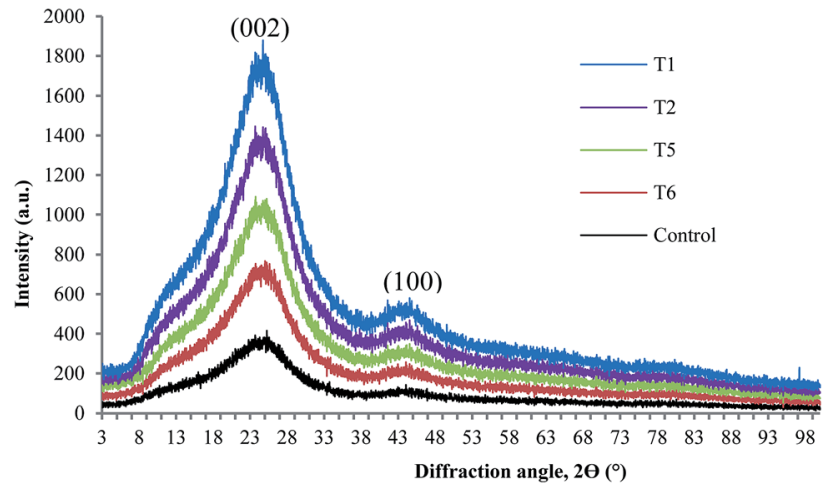

Fig. 8 WAXD spectra of untreated and variously pretreated wool fibre that have been pyrolysed at $800^{\circ} \mathrm{C}$.

Table 4 Structure parameters of $X$-ray diffraction for fibres produced from various pre-treated wool fibre by pyrolysis

\begin{tabular}{llllll}
\hline Treatment & $d_{(002)}(\mathrm{nm})$ & $d_{(100)}(\mathrm{nm})$ & $L_{\mathrm{c}}(\mathrm{nm})$ & $L_{\mathrm{c}} / d_{(002)}(\mathrm{nm})$ & $L_{\mathrm{a}}(\mathrm{nm})$ \\
\hline Untreated & 0.3646 & 0.2196 & 0.7449 & 2.0431 & 1.5399 \\
T1 & 0.3682 & 0.2243 & 0.7295 & 1.9813 & 1.5082 \\
T2 & 0.3660 & 0.2188 & 0.7507 & 2.0511 & 1.5521 \\
T5 & 0.3724 & 0.2210 & 0.7904 & 2.1224 & 1.6341 \\
T6 & 0.3696 & 0.2209 & 0.7678 & 2.0774 & 1.5873
\end{tabular}

was observed for the treatment $\mathrm{T} 1$ and the highest for the Sample T5. Sample T5 showed the highest value of $d_{002}$ but the Sample T2 showed the lowest. The numerical variation of $d_{002}$ is greater than that of $d_{100}$, which is similar to the results of common carbon materials. The value of $L_{\mathrm{c}}, L_{\mathrm{c}} / d_{002}$ and La also increased because of the pre-treatments in comparison with the carbon fibre made from the control wool except the lignin treated wool (Sample T1). The results indicate that the pretreatment of wool affected the crystal structure of the carbon fibre produced from wool.

Table 4 shows the effect of various pre-treatments on the value of $d_{002}, d_{100}, L_{\mathrm{c}}$ and $L_{\mathrm{a}}$. The average value of interlayer $d$ spacing of the graphitic basal planes obtained from the position of the (002) peak and (100) peak for the control is 0.3646 and 0.2196 respectively, thus reflecting the presence of nongraphitic carbon only.

\section{Conclusions}

We demonstrated that wool fibre could be used as a carbon fibre precursor and also various pre-treatments investigated here had positive effect on the carbon fibre yield and tensile strength of the resultant carbon fibre. Of the chemical treatments investigated, lignin-treated wool fibre exhibited the highest carbon yield but the carbon fibre produced from the chlorine-Hercosett treated wool fibre showed the highest tensile strength and also elongation at break. Generally, the surface of the carbon fibre produced from wool fibre was highly hydrophilic except from lignin-treated and chlorine-Hercosett-treated wool fibre which exhibited hydrophobicity. The surface of the more hydrophilic carbon fibre was shown to have a greater proportion of hydroxyl groups. The carbon fibre produced from the untreated and variously pre-treated wool fibre formed a ribbonlike morphology while that from lignin pre-treated wool fibre was almost perfectly circular. The developed carbon fibres may find application in thermoplastic and thermoset composite products.

\section{Acknowledgements}

The authors gratefully acknowledge financial assistance from AgResearch Ltd., through AgResearch Pre-Seed Fund (A19526). The authors are grateful to Matthew Polson, Vladimir Golovko and Mike Flaws (all from the University of Canterbury) for TGA, pyrolysis experiments, and FESEM respectively. We would like to thank Alex Holman (Curtin University of Technology) for the Py-GC/MS analysis.

\section{References}

1 P. Morgan, Carbon fibres and their Composites, CRC Press, Taylor \& Francis Group, LLC, 2005, p. 269.

2 A. Barrero, J. Bedia, T. Cordero, M. Lallave, I. G. Loscertales, J. Rodriguez-Mirasol and R. Ruiz-Rosas, Carbon, 2010, 48, 696.

3 H. Endoc, T. Fana, T. Fujino, T. Hirose, T. Okabe and M. Yoshimura, Carbon, 2002, 40, 761.

4 J. F. Kadla, S. Kubo, R. A. Venditti, R. D. Gilbert, A. L. Compere and W. L. Griffith, Carbon, 2002, 40, 2913.

5 Q. Wu and D. Pan, Text. Res. J., 2002, 72, 405.

6 D. Cho, D. Kim and J. M. Kim, Mater. Lett., 2013, 104, 24.

7 L. Deng, R. J. Young, I. A. Kinloch, Y. Q. Zhu and S. J. Eichhorn, Carbon, 2013, 58, 66.

8 X. Ma, C. Yuan and X. Liu, Materials, 2014, 7, 75.

9 X. Xu, J. Zhou, L. Jiang, G. Lubineau, Y. Chen, X.-F. Wu and R. Piere, Mater. Lett., 2013, 109, 175.

10 A. L. Compere, W. L. Griffith, C. F. Leitten Jr and J. T. Shaffer, Int. SAMPE Tech. Conf., 2001, 33, 1306.

11 M. Zhang and A. A. Ogale, Carbon, 2014, 69, 626.

12 M. Thunga, K. Chen, D. Grewell and M. Kessler, Carbon, 2014, 68, 159.

13 S. P. Maradur, C. H. Kim, S. Y. Kim, B.-H. Kim, W. C. Kim and K. S. Yang, Synth. Met., 2012, 162, 453.

14 J. L. Braun, K. L. Holtman and J. F. Kadla, Carbon, 2005, 43, 385.

15 P. Bajpai, Update on Carbon Fibre, Smithers Rapra Publishing, Akron, OH, 2013.

16 X. Huang, Materials, 2009, 2, 2369.

17 H. Kajiura, Y. Tanabe and E. Yasuda, Carbon, 1997, 35, 169. 18 N. Miyajima, T. Akatsu, T. Ikoma, O. Ito, B. Rand and Y. Tanabe, Carbon, 2000, 38, 1931.

19 R. S. Labruqu, H. Blanchard, R. Pailler and R. Naslain, J. Eur. Ceram. Soc., 2002, 22, 1001.

20 M. B. Wu, Y. Y. Ren, N. Guo, S. B. Li, X. Y. Sun, M. H. Tan, D. Wang, J. T. Zheng and N. Tsubaki, Mater. Lett., 2012, 82, 124 . 
21 M. M. R. Khan, Y. Gotoh, H. Morikawa, M. Miura, Y. Fujimori and M. Nagura, Carbon, 2007, 45, 1035.

22 D. Y. Kim, Y. Nishiyama, M. Wada and S. Kuga, Cellulose, 2001, 8, 29.

23 M. M. Hassan and J. R. McLaughlin, ACS Appl. Mater. Interfaces, 2013, 5, 1548.

24 A. N. Parbhu, W. G. Bryson and R. Lal, Biochemistry, 1999, 38, 11755.

25 W. Chen, X. Liu, R. L. He, T. Lin, Q. F. Zeng and X. G. Wang, Powder Technol., 2013, 234, 76.

26 G. Laufer, C. Kirkland, A. B. Morgan and J. C. Grunlan, ACS Macro Lett., 2013, 2, 361.

27 M. R. Zachariah and O. I. Smith, Combust. Flame, 1987, 69, 125.

28 C. L. Rasmussen, P. Glarborg and P. Marshall, Proc. Combust. Inst., 2007, 31, 339.

29 M. W. Beach, N. G. Rondah, R. D. Froese, B. B. Gerhart, J. G. Green, B. G. Stobby, A. G. Shmakov, V. M. Shvartsberg and O. P. Korobeinchev, Polym. Degrad. Stab., 2008, 93, 1664.

30 J. M. Cardamone, J. Yao and A. Nuñez, Text. Res. J., 2004, 74, 555.

31 E. I. El-Shafey, Water, Air, Soil Pollut., 2005, 163, 81.

32 J. A. Schwarz, C. I. Contescu and K. Putyera, Dekker Encyclopedia of Nanoscience and Nanotechnology, Marcel Dekker, Inc., New York, 2004, vol. 5, p. 3355.
33 L. Lin, M. Yoshioka, Y. Yao and N. Shiraishi, J. Appl. Polym. Sci., 1995, 55, 1563.

34 D. D. Edie, Carbon, 1998, 36, 345.

35 V. V. Kadam, V. Goud and D. B. Shakyawar, Indian J. Fibre Text. Res., 2013, 38, 410.

36 C. M. Tian, Z. Li, H. Z. Guo and J. Z. Xu, J. Fire Sci., 2003, 21, 155.

37 E. Manefee and L. Yee, Text. Res. J., 1965, 35, 801.

38 C. Popescu and P. Augustin, J. Therm. Anal. Calorim., 1999, 57, 509.

39 E. Senoz, R. P. Wool, C. J. M. McChalicher and C. K. Hong, Polym. Degrad. Stab., 2012, 97, 297.

40 N. Galios, J. Templier and S. Derenne, J. Anal. Appl. Pyrolysis, 2007, 80, 216.

41 P. J. Goodhew, A. J. Clarke and J. E. Bailey, Mater. Sci. Eng., 1975, 17, 3 .

42 A. M. Sookne and M. Harris, Text. Res. J., 1939, 9, 437.

43 M. G. Huson, J. S. Church, A. A. Kafi, A. L. Woodhead, J. Khoo, M. S. R. N. Kiron, J. E. Bradby and B. L. Fox, Carbon, 2014, 68, 240.

44 R. G. Karunakaran, C. H. Lu, Z. Zhang and S. Yang, Langmuir, 2011, 27, 4594.

45 J. Fan and Y. Zhao, Langmuir, 2010, 26, 8245. 